\title{
Impact of olive oil and honey on healing of diabetic foot: a randomized controlled trial
}

This article was published in the following Dove Press journal:

Clinical, Cosmetic and Investigational Dermatology

\author{
Zohreh Karimi ${ }^{1,2}$ \\ Mohammad \\ Behnammoghadam ${ }^{3,4}$ \\ Hossein Rafiei ${ }^{5}$ \\ Naeem Abdi ${ }^{6,7}$ \\ Mohammad Zoladi ${ }^{8}$ \\ Mohammad Sharif \\ Talebianpoor ${ }^{9}$ \\ Arash Arya ${ }^{10}$ \\ Maryam Khastavaneh ${ }^{8}$ \\ 'Department of Operating Room, School \\ of Paramedicine, Yasuj University of \\ Medical Sciences, Yasuj, Iran; ${ }^{2}$ Deputy \\ Education School of Paramedicine, Yasuj \\ University of Medical Sciences, Yasuj, \\ Iran; ${ }^{3}$ Medicinal Plants Research Center, \\ Yasuj University of Medical Sciences, \\ Yasuj, Iran; ${ }^{4}$ Center of Disease Registry, \\ Yasuj University of Medical Sciences, \\ Yasuj, Iran; ${ }^{5}$ Social Determinants of \\ Health Research Center, Qazvin \\ University of Medical Sciences, Qazvin, \\ Iran; ${ }^{6}$ Department of Critical Care \\ Nursing, Yasuj University of Medical \\ Sciences, Yasuj, Iran; ${ }^{7}$ School of \\ Paramedicine, Yasuj University of Medical \\ Sciences, Yasuj, Iran; ${ }^{8}$ Department of \\ Nursing, Yasuj University of Medical \\ Sciences, Yasuj, Iran; ${ }^{9}$ Department of \\ Pharmacology, Yasuj University of Medical \\ Sciences, Yasuj, Iran; ${ }^{10}$ Department of \\ Internal Medicine, School of Medicine, \\ Yasuj University of Medical Sciences, \\ Yasuj, Iran
}

Correspondence: Mohammad Behnammoghadam

Medicine Plants Research Center, Yasuj University of Medical Sciences, Next to Imam Sajad Hospital, Bagher Street, Yasuj, Iran

Tel +98 7433236172

Fax +98743323401 I

Email mbehnam1363@gmail.com
Background: This study aimed 1) to examine the impact of honey on diabetic foot; 2) to examine the effect of olive oil on diabetic foot; and 3) to compare the impact of honey and olive oil in the healing of diabetic foot.

Methods: In this randomized controlled trial, 45 patients took part. Patients were randomly assigned to three groups. In the honey group, the wound was dressed using gauzes with honey daily for 1 month. In the olive oil group, the wound was dressed using gauzes with olive oil $(4 \mathrm{~mL})$ daily for 1 month. Patients in the control group received usual dressing. Wounds were assessed before and after intervention using the Wagner scoring system and the checklist of diabetic foot healing (where a higher score indicates better wound healing).

Results: Demographic characteristics of patients in the three groups were similar. Mean scores of tissue around the wound, wound grade, wound drainage, and wound healing were similar before intervention in all three groups. After intervention, means score of tissue around the wound, wound grade, wound drainage, and wound healing were significantly higher in patients in the honey and olive oil groups compared to patients in the control group. Conclusion: The results of this study reveal that honey is as effective as olive oil in the treatment of diabetic foot. Given the few studies on this topic, further investigation is needed.

Keywords: foot ulcer, olive oil, therapeutic use, honey

\section{Introduction}

Diabetic foot is a serious complication of diabetes, which can result in prolonged hospitalization and amputation of the lower limb in many cases. ${ }^{1}$ Studies have shown that more than $15 \%$ of people with diabetes suffer from diabetic foot. ${ }^{2}$ The annual incidence of diabetic foot is estimated at $25-80 \%{ }^{3}$ The worldwide prevalence of diabetic foot has been reported to be $4-27 \% .{ }^{4}$ In developed countries, more than $5 \%$ of people with diabetes suffer from diabetic foot, and $20 \%$ of healthcare resources are spent on the care of diabetic foot. In the USA, the cost of diabetic foot is 7,000-10,000 USD, and this figure is increased by 65,000 USD in complicated cases needing amputation, which indicates the high costs of healthcare. ${ }^{5}$

Diabetic foot results from ischemia, neuropathy, and infection. Despite medical and surgical advances in recent decades, problems related to diabetic foot are the most important complications of diabetes. It has also remained a health issue and is considered the greatest risk factor for non-traumatic amputation in the foot. ${ }^{6}$ Lack of healing of diabetic foot can result in infection, gangrene, amputation, and even death. ${ }^{7}$ Diabetic foot heals infrequently and affects lifestyle, social activities, health, and quality of life in patients and their caregivers. ${ }^{8}$ It can also result in increasing 
healthcare costs. ${ }^{9}$ Treatment of diabetic foot includes control of blood sugar, antibiotic therapy, wound debridement, hyperbaric oxygen, negative pressure, electrical stimulation, and using growth hormone. ${ }^{3}$

Diabetic foot is an important factor in the mortality and disability of people with diabetes. Despite many advances in the diagnosis and treatment of diabetes, the issue of diabetic foot has not been resolved. Many patients suffer from some degree of diabetic foot; consequently, they are treated with medication. After ineffective medical treatment, surgery is considered for patients. ${ }^{10}$ One of the most challenging tasks in the healthcare of diabetic foot is dressing of these wounds. Various products are used to heal diabetic foot, and their efficiency and effectiveness have been investigated in many studies. Olive oil and honey are two examples of such products. ${ }^{4,11,12}$

Investigations revealed that olive oil probably improves total tissue blood flow and reduces inflammation, thus leading to ulcer healing. ${ }^{4}$

Another study showed that honey has broad-spectrum bactericidal properties, aids in the management of wound infection, enhances the proliferation of epithelium, and absorbs edema around the wound. ${ }^{9}$

A systematic review showed that honey dressing may be effective in decreasing the overall treatment time and mean clearance time of wounds, and increasing the bacterial clearance rate and the healed area of wounds. ${ }^{11}$

The application of complementary and alternative medicine in wound healing has increased over the past decade. Using honey and olive oil dressings are two examples. However, previous studies on these agents recommended further investigation. We did not find any studies comparing the effects of these two products on diabetic foot healing. This study aimed 1) to examine the impact of honey on diabetic foot; 2) to examine the effect of olive oil on diabetic foot; and 3) to compare the impact of honey and olive oil in the healing of diabetic foot.

\section{Methods}

\section{Study design}

This clinical trial was conducted in Yasuj City, Iran. This study was also recorded in the Iran Clinical Trials database (number IRCT 2016082928017N3).

Inclusion criteria for this study were: grade I or II diabetic foot based on the Wagner scale; age 20-70 years; having a wound in the feet (toes, sole, and heel) for more than 1 month; no history of alcohol intake, cigarette smoking, or drug abuse; no history of taking medications that interfere with wound healing, such as immunosuppressants or corticosteroids; and no history of comorbidities that may interfere with wound healing, such as cancer, vasculitis, or failure of the kidney, liver, or heart. Patients with the following features were excluded from the study: a history of allergy to olive oil or honey, having wounds or active infection needing antibiotic therapy, or gangrene needing amputation.

\section{Setting and sample}

All 45 patients who were referred to hospitals affiliated to Yasuj University of Medical Sciences were selected to take part in the study. The sample size was set to 45 individuals based on calculations and the inclusion of $20 \%$ probable dropouts. The sample size was determined based on the formula:

$$
n=\frac{\left(Z_{1-\alpha / 2}+Z_{1-\beta}\right)^{2}\left[P_{1}\left(1-P_{1}\right)+P_{2}\left(1-P_{2}\right)\right]}{\left(P_{1}-P_{2}\right)^{2}}
$$

First, a list of patients was provided from the hospitals. Then, the investigator explained the objectives of the study to the potential participants and invited them to take part in the study. After agreeing to participate in the study, the patients provided written informed consent, and this was conducted in accordance with the Declaration of Helsinki. Among 57 available patients, 45 patients who met the inclusion criteria were selected using a non-random sampling method. The samples were based on parallel and random allocation of block randomization. Patients were randomly assigned to the three groups of honey, olive oil, and control. Randomized participant stratification was conducted by one of the nurses working in the clinic who was not involved in any aspects of this study.

\section{Ethical considerations}

This study was conducted under the supervision of the Ethics Committee of Yasuj University of Medical Sciences. An informed consent form was obtained from all participants. Participation in the study was voluntary. Information was kept confidential at all stages, and no patient names were provided at any stage of the study.

Approval was obtained from the Ethics Committee of Yasuj University of Medical Sciences (IR.YUMS. REC.1395,80). 


\section{Measurements and instruments}

This study used the following three instruments:

1. Checklist of demographic information, including age, gender, marital status, level of education, body mass index, employment status, history of diabetes, duration of wound (months), location of wound, and fasting blood sugar level. Items on this checklist were reviewed by five experts in nursing and medicine who have experience in the treatment and care of diabetic patients.

2. Grading system of diabetic foot: diabetic foot is classified based on the Wagner scoring system. In this study, Wagner grading, a standard tool, was used to identify active diabetic foot in the subjects. Based on this scale, patients' wounds were classified into:

1. grade 0: pre-wound lesions, healed wounds, and existing bone changes

2. grade I: superficial wound without subcutaneous involvement

3. grade II: subcutaneous tissue which may extend to bone, tendon, ligament, or joint capsule

4. grade III: deep wound with abscess, osteomyelitis with joint infection

5. grade IV: localized gangrene in the toes or heel

6. grade V: gangrene of the whole foot that needs amputation. $^{13}$

A good level of validity and reliability of the Persian version of the Wagner grading system has been determined in a previous study by Hadadi et al. ${ }^{14}$

1. Checklist of diabetic foot healing: this checklist assesses four variables of wound grading, wound color, status of tissues around the wound, and status of wound drainage. Based on this checklist, the score of each parameter is 100 , which is divided between components of each parameter. The total score is 400 , which indicates healing of the wound. The minimum score is 50 , which indicates deterioration of the wound. Based on this checklist, wound healing is classified into:

1. Complete healing: total score is 400 based on the checklist.

2. Partial healing: total score has increased by a minimum of 30 points compared to the initial point.
3. Lack of healing: wound score has not changed compared to the initial point or has changed by less than 30 points.

4. Aggravation: wound score has decreased by a minimum of 10 points compared to the initial point.

A good level of validity and reliability of the Persian version of this checklist has been determined in a previous study by Nasiri et al. ${ }^{4}$

\section{Data collection and procedure}

In the honey group, the wound was first irrigated using sterile normal saline based on hospital routines. Then the wound was dressed using gauzes with honey. This type of dressing continued daily for 1 month. The honey used in the study was purchased from a honey-producing firm in Iran. In the olive oil group, the wound was first irrigated using normal saline based on hospital routines. Then the wound was dressed using gauzes with olive oil ( $4 \mathrm{~mL})$. This type of dressing continued daily for 1 month. The olive oil used in the study was purchased from an olive-oil producing firm in Iran. The control group received no intervention; only routine hospital care was carried out, which included daily irrigation using sterile normal saline and dressing with sterile gauze. This type of dressing continued daily for 1 month.

\section{Data analysis}

Data were analyzed using SPSS software version 18. Statistical tests were used, including descriptive statistics, chi-squared test for comparing the distribution of frequencies in qualitative variables, paired $t$-test for within-group comparison of wound variables, ANOVA for between-group comparisons of mean wound variables with a normal distribution, and Kruskal-Wallis for between-group comparisons of wound variables without a normal distribution.

\section{Results}

Demographic characteristics of patients, including age, gender, educational level, marital status, body mass index, location of wound, treatment type for diabetes, and ethnicity were similar in the three groups $(p>0.05)$ (Table 1$)$.

\section{Honey group (within-group comparison)}

The mean blood sugar level in the honey group before and after the intervention was 156.2 and $138.0 \mathrm{mg} / \mathrm{dL}$, respectively $(p>0.05)$. The mean wound grade in these patients 
Table I Participants' demographic characteristics

\begin{tabular}{|c|c|c|c|c|c|}
\hline \multicolumn{2}{|l|}{ Item } & \multirow{2}{*}{$\begin{array}{l}\text { Olive oil, n (\%) } \\
\text { I (6.7) }\end{array}$} & \multirow{2}{*}{$\begin{array}{l}\text { Honey, } \\
\text { n (\%) } \\
\text { I (6.7) }\end{array}$} & \multirow{2}{*}{$\begin{array}{l}\text { Usual dressing, } \\
\text { n (\%) } \\
2(13.3)\end{array}$} & \multirow{2}{*}{$\begin{array}{l}p \text {-Value } \\
0.27\end{array}$} \\
\hline Age (years) & $30-39$ & & & & \\
\hline & $40-49$ & $6(40)$ & I (6.7) & I (6.7) & \\
\hline & $50-59$ & $3(20)$ & $8(53.3)$ & $6(40)$ & \\
\hline & $60-69$ & $3(20)$ & $2(13.3)$ & $4(26.7)$ & \\
\hline & $70-79$ & $2(13.3)$ & $3(20)$ & $2(13.3)$ & \\
\hline \multirow[t]{2}{*}{ Gender } & Male & I3 (86.7) & $9(60)$ & $9(60)$ & 0.19 \\
\hline & Female & $2(13.3)$ & $6(40)$ & $6(40)$ & \\
\hline \multirow[t]{2}{*}{ Educational level } & Below diploma & $6(40)$ & $9(60)$ & $8(53.3)$ & 0.54 \\
\hline & Diploma and higher & $9(60)$ & $6(40)$ & $7(46.7)$ & \\
\hline \multirow[t]{2}{*}{ Marital status } & Single & $2(13.3)$ & I (6.7) & $3(20)$ & 0.56 \\
\hline & Married & $13(86.7)$ & $14(93.3)$ & $12(80)$ & \\
\hline \multirow[t]{3}{*}{ Body mass index $\left(\mathrm{kg} / \mathrm{m}^{2}\right)$} & $18-24$ & I (6.7) & $0(0)$ & $2(13.3)$ & 0.65 \\
\hline & $25-29$ & $6(40)$ & $8(53.3)$ & $6(40)$ & \\
\hline & $30-35$ & $8(53.3)$ & $7(46.7)$ & $7(46.7)$ & \\
\hline \multirow[t]{4}{*}{ Location of wound } & Sole & $2(13.3)$ & $5(33.3)$ & $5(33.3)$ & 0.14 \\
\hline & Heel & $6(40)$ & $2(13.3)$ & I (6.7) & \\
\hline & Toes & $4(26.7)$ & I (6.7) & $4(26.7)$ & \\
\hline & On the toe & $3(20)$ & $7(46.7)$ & $5(33.3)$ & \\
\hline \multirow[t]{3}{*}{ Treatment type for diabetes } & Metformin & $9(60)$ & $7(46.7)$ & $8(53.3)$ & 0.96 \\
\hline & Insulin & $4(26.7)$ & $5(33.3)$ & $4(26.7)$ & \\
\hline & Both treatments & $2(13.3)$ & $3(20)$ & $3(20)$ & \\
\hline \multirow[t]{4}{*}{ Ethnicity } & Lor & $7(46.7)$ & $9(60)$ & $9(60)$ & 0.78 \\
\hline & Fars & $2(13.3)$ & $3(20)$ & I (6.7) & \\
\hline & Tork & $5(33.3)$ & $2(13.3)$ & $3(20)$ & \\
\hline & Other & I (6.7) & I (6.7) & $2(13.3)$ & \\
\hline
\end{tabular}

before and after the intervention was 65.5 and 89.5, respectively $(p<0.0001)$; the mean score of tissue around the wound was 61.5 and 90.5, respectively $(p<0.0001)$; the mean score of wound drainage was 97.0 and 75.0, respectively $(p<0.0001)$; and the mean score of wound healing was 267.5 and 371.5 , respectively $(p<0.0001)$. Increases in mean scores in patients after intervention indicate better wound healing. Images of the wound before and after intervention with honey are shown in Figures 1 and 2, respectively.

\section{Olive oil group (within-group comparison)}

The mean blood sugar level in the olive oil group before and after the intervention was 156.5 and $147.9 \mathrm{mg} / \mathrm{dL}$, respectively $(p>0.05)$. The mean wound grade in these patients before and after the intervention was 63.5 and 82.5 , respectively $(p<0.0001)$; the mean score of tissue around the wound was 57.0 and 83.0, respectively $(p<0.0001)$; the mean score of wound drainage was 69.0 and 89.0, respectively $(p<0.0001)$; and the mean score of wound healing was 253.0 and 330.5 , respectively $(p<0.0001)$. Increases in mean scores in patients after the intervention indicate better wound healing. Images of the wound before and after intervention with olive oil are shown in Figures 3 and 4, respectively.

\section{Control group (within-group comparison)}

The mean blood sugar level in the control group before and after the intervention was 170.7 and $153.1 \mathrm{mg} / \mathrm{dL}$, respectively $(p>0.05)$ (Figure 5). The mean wound grade in these patients before and after the intervention was 67.0 and 64.5 , respectively ( $p=0.36$ ); the mean score of tissue around the wound was 67.0 and 64.5, respectively ( $p=0.74)$; the mean score of wound drainage was 77.0 and 74.0 , respectively $(p=0.43)$; and the mean score of wound healing was 277.5 and 268.0, respectively ( $p=0.57$ ) (Figure 6). Decreases in mean scores in patients after the intervention indicate no wound healing. Images of the wound before and after intervention in the control group are shown in Figures 5 and 6, respectively. 


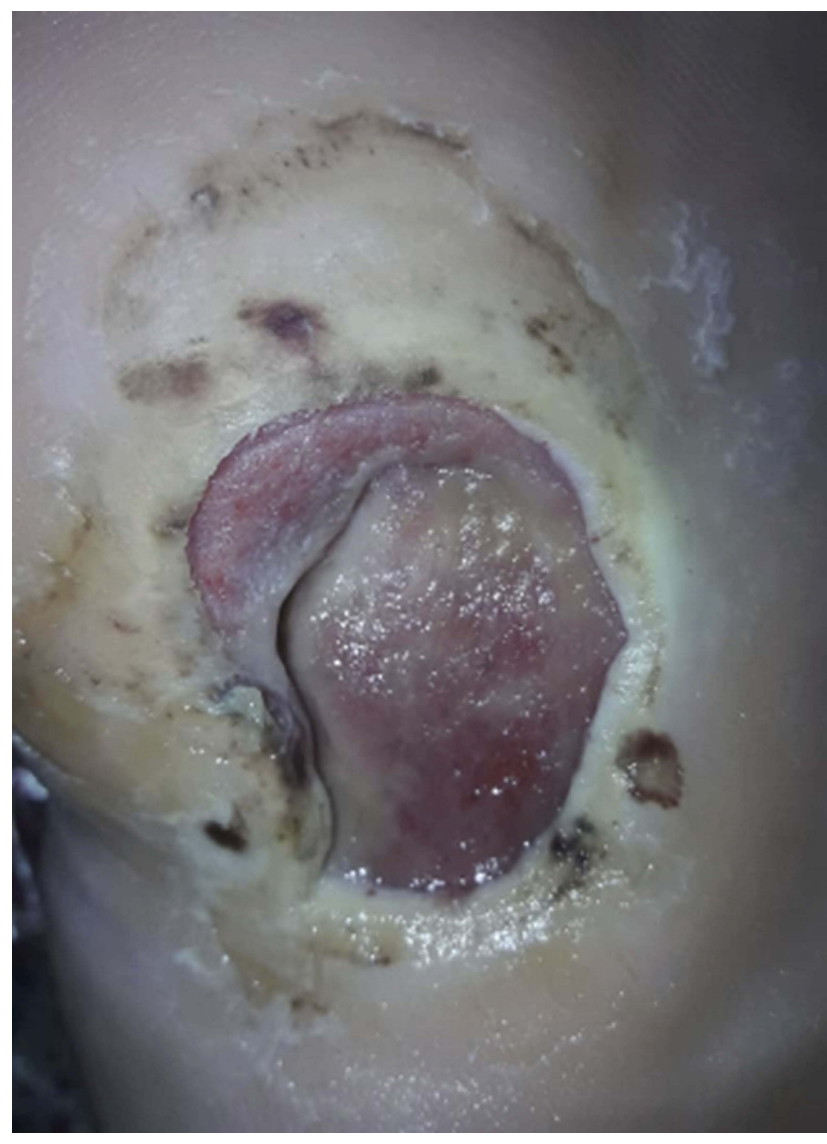

Figure I Before intervention with honey.

\section{Comparison between groups before the intervention}

Before the intervention, the mean blood sugar level in the honey, olive oil, and control groups was 156.2, 156.5, and $170.7 \mathrm{mg} / \mathrm{dL}$, respectively $(p=0.74)$. The mean wound grade in these three groups before the intervention was $65.5,63.5$, and 67.0 , respectively $(p=0.69)$; the mean score of tissue around the wound was 61.5, 57.0, and 67.0, respectively $(p=0.67)$; the mean score of wound drainage was 75.0, 69.0, and 77.0, respectively $(p=0.57)$; and the mean score of wound healing was 267.5, 253.0, and 277.0, respectively $(p=0.57)$ (Figure 7$)$. Results of the one-way ANOVA showed no significant differences between groups in terms of the mentioned variables $(p>0.5)$.

\section{Comparison between groups after the intervention}

After the intervention, the mean blood sugar level in the honey, olive oil, and control groups was 138.0, 147.9, and $153.1 \mathrm{mg} / \mathrm{dL}$, respectively $(p=0.69)$. The mean wound grade in these three groups after the intervention was

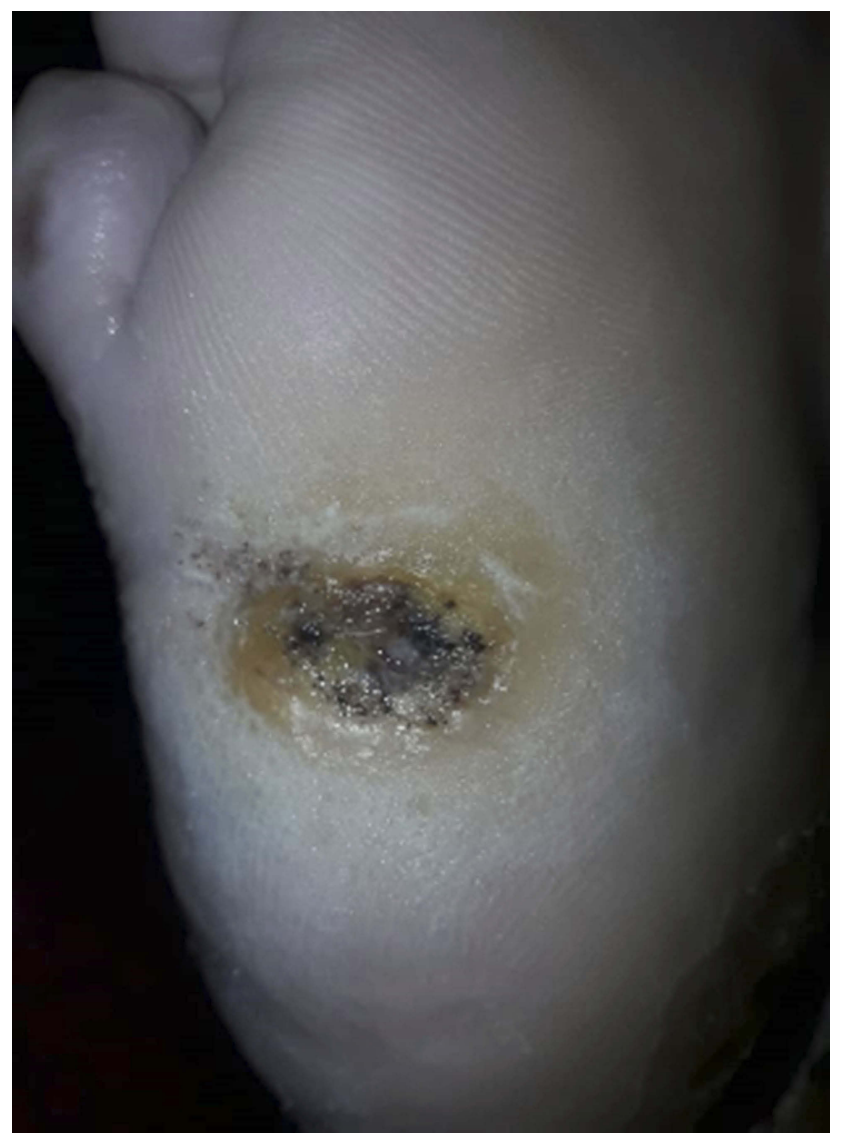

Figure 2 After intervention with honey.

$87.3,82.7$, and 66.3 , respectively $(p<0.0001)$; the mean score of tissue around the wound was 90.5, 83.0, and 64.5, respectively $(p=0.02)$; the mean score of wound drainage was 97.0, 89.0, and 74.0, respectively $(p=0.02)$; and the mean score of wound healing was 371.5, 330.5, and 268.0, respectively ( $p=0.002)$ (Figure 7).

\section{Discussion}

Diabetic foot is a major challenge in people with diabetes. This study aimed to find answers to three questions: 1) Does honey dressing affect the healing of diabetic foot? 2) Does olive oil dressing affect the healing of diabetic foot? 3) Is there any difference between the healing power of honey and olive oil in diabetic foot (main objective of the study)?

In terms of the first study question, the results showed that using honey is effective in the treatment of diabetic foot. Several studies have been conducted on diabetic foot; however, there are limitations in these studies that affect the generalizability of the findings. In a descriptive study, Surahio et al examined the impact of honey on diabetic foot in 174 patients. Their results showed that using honey in the treatment of diabetic foot significantly improves the process 


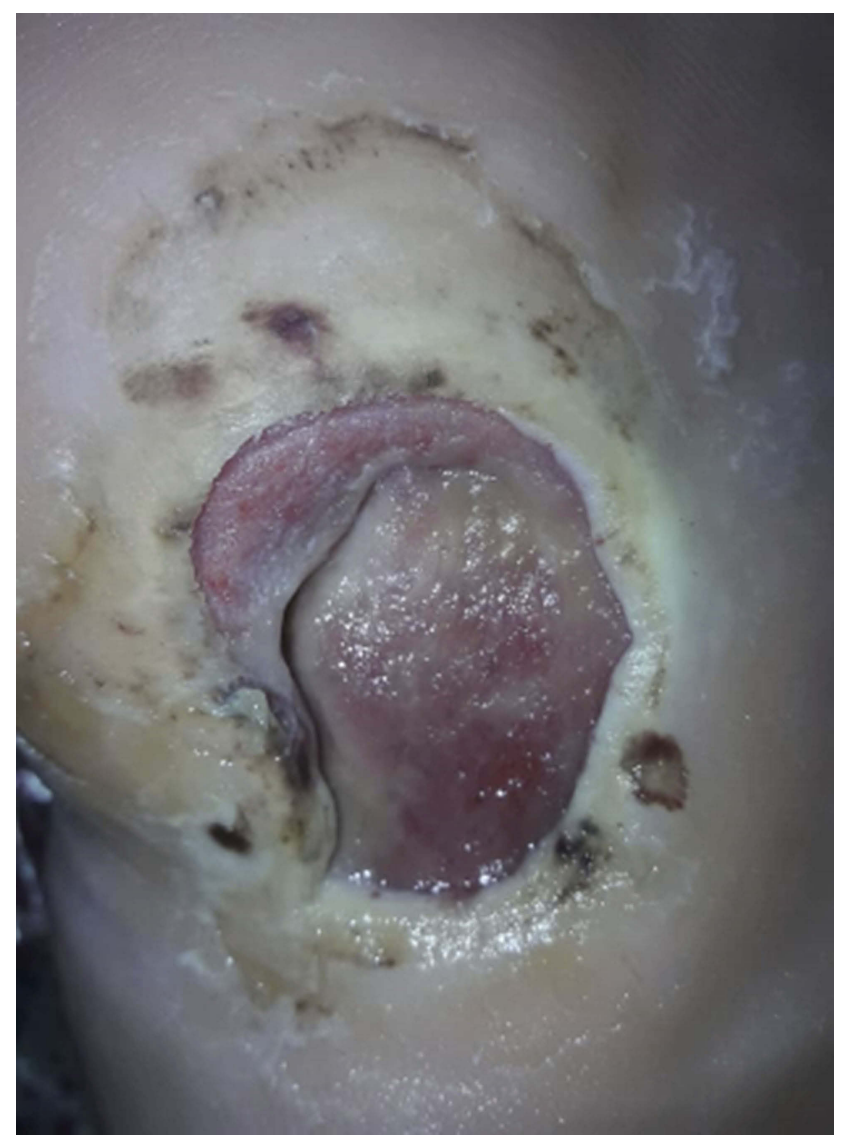

Figure 3 Before intervention with olive oil.

of wound healing in these patients. ${ }^{15}$ In another report of a case series, Mohamed et al examined the effect of honey dressing on the healing of diabetic foot, pain, and cost of dressing, and found that honey has a significant impact on improving diabetic foot; consequently, pain and costs of healthcare were decreased considerably. ${ }^{16}$ The healing properties of honey can be explained by its antimicrobial and antiinflammatory effects, moisturizing in the wound bed, osmotic effects, decreasing edema in the cells of the wound, accelerating the process of angiogenesis and granulation in the wound, accelerating collagenases and epithelialization in the wound, increasing activities of lymphocytes and phagocytes, and accelerating debridement of necrotic tissue. ${ }^{11,16-18}$

Regarding the second study question, the results of the study showed that using olive oil in diabetic foot can improve the process of wound healing. Few studies have been conducted on the impact of olive oil on diabetic foot. In a clinical trial, Nassiri et al examined the impact of olive oil on the healing of diabetic foot. In their study, 34 patients were assigned to intervention and control groups. Olive oil was used in dressing of the intervention group. The results showed that using olive oil can help in the treatment of diabetic foot. ${ }^{4}$ In

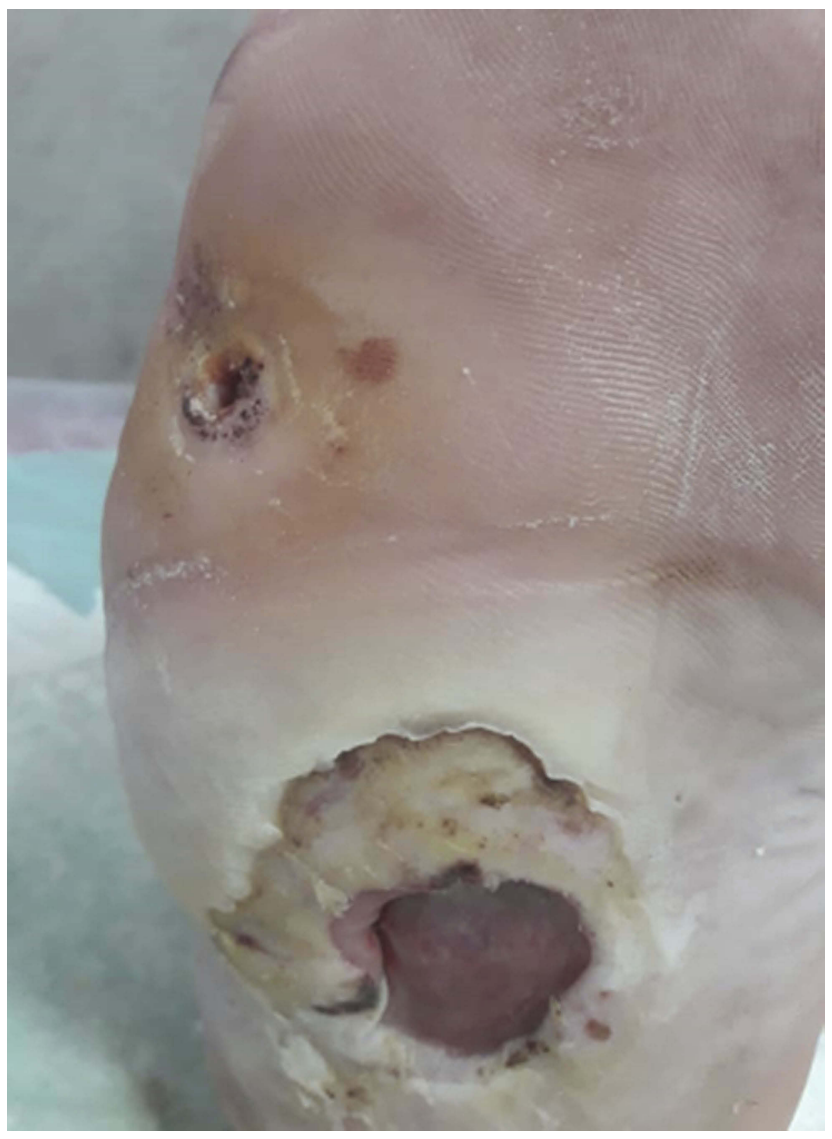

Figure 4 After intervention with olive oil.

another study, Elshenawie et al examined the impact of ozone olive oil ointment dressing on diabetic foot in 30 patients. The results showed that using this ointment improves the healing of diabetic foot considerably compared to routine dressing. ${ }^{19}$ Although the mechanism of effect of olive oil in the process of wound healing is not clear, it seems that it occurs through two mechanisms. Olive oil contains essential fatty acids such as linoleic acid and linolenic acid, which stimulate cell healing and accelerate the process of wound healing. Olive oil also has antioxidant, antimicrobial, and anti-inflammatory features, which improve the formation of epithelial tissues in the wound and accelerate the process of wound healing. ${ }^{20}$

Regarding the third objective of the study, the results showed that wound healing was the same in patients in the honey and olive oil groups. Indeed, these two substances had similar effects on wound healing. No previous study was found comparing these two substances. However, concurrent use of honey and olive oil has been reported in some case reports. In one study, Khadem Haghighian et al reported a case of healing of diabetic foot using olive oil and honey wax concurrently. The patient was diabetic, with a diabetic wound of $2 \mathrm{~cm}$ 


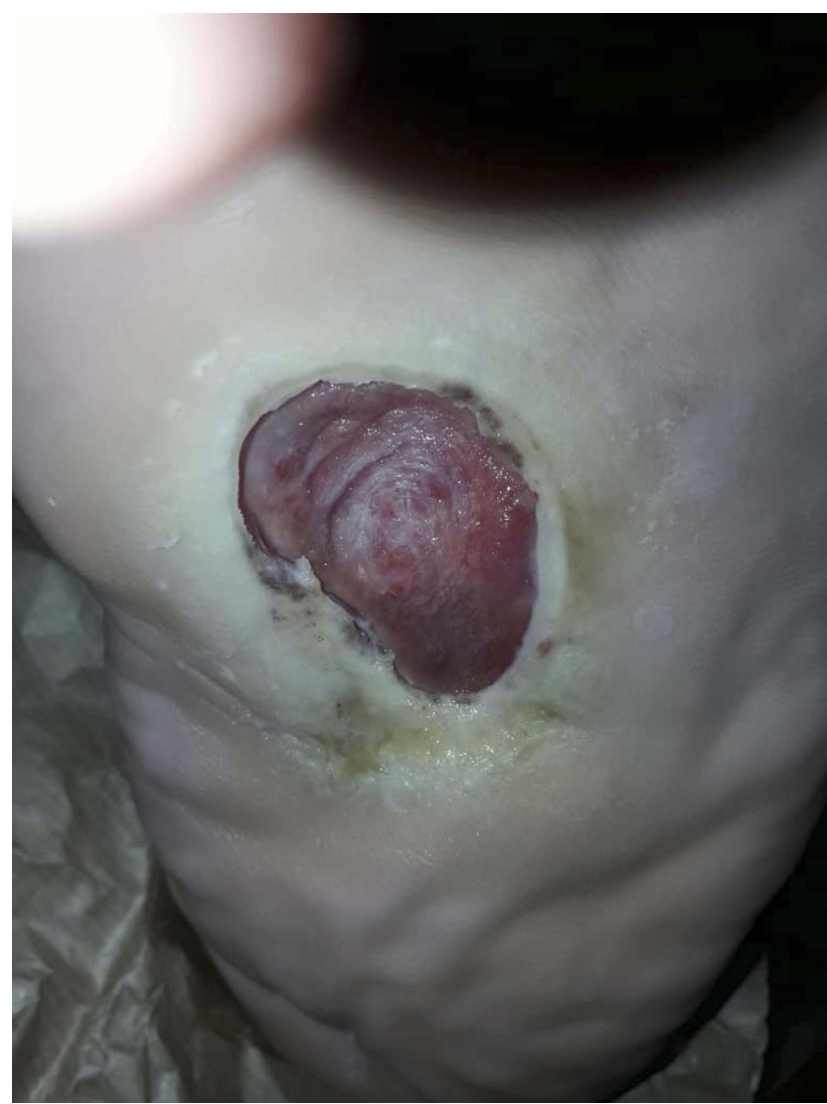

Figure 5 Before intervention in the control group.

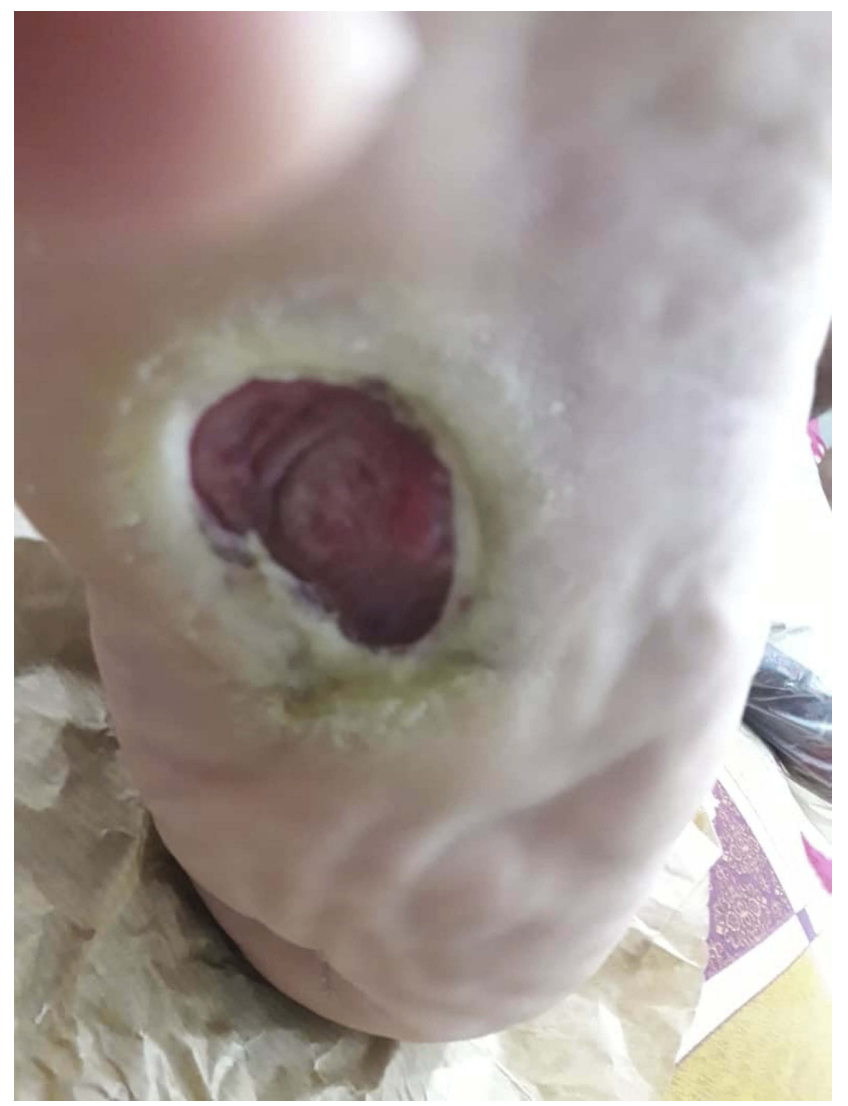

Figure 6 After intervention in the control group.

$\longrightarrow$ Honey --m--O Olive oil $\cdots \cdot \cdots \cdot$ Control group

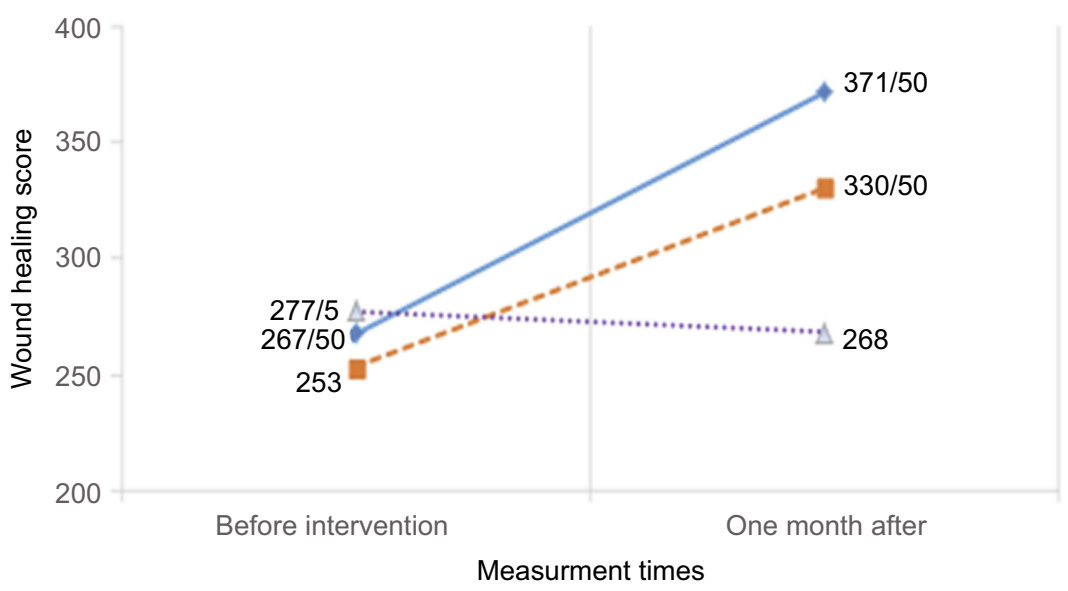

Figure 7 Wound healing before and after intervention in patients in three groups.

length $\times 1 \mathrm{~cm}$ width $\times 1 \mathrm{~cm}$ depth. The results showed that using this combination led to complete healing of the wound over 2 weeks. $^{21}$ In another case study, Zahmatkesh and Rashidi examined the impact of concurrent use of honey and olive oil on healing of a diabetic foot of $2 \times 2 \mathrm{~cm}$ area and $2 \mathrm{~cm}$ depth in the calf. Treatment included daily dressing with a mixture of heated honey and olive oil. The results showed that granulation tissue was created in the wound after 5 days, and the wound healed completely over 1 month. ${ }^{22}$ 


\section{Limitations}

The low sample size is a limitation of our study. Because of the waxy nature of the olive oil and honey, we could not use a placebo in the control group.

\section{Conclusion}

Proper and cost-effective treatment of diabetic foot can significantly improve the quality of life in these patients. This is especially important for patients in developing countries because of limited financial resources. The results of this study revealed that honey is as effective as olive oil in the treatment of diabetic foot. Given the few studies on this topic, further investigation is needed. It is also suggested that the effectiveness of the two methods of treatment should be followed up over 6 or 12 months.

\section{Data sharing statement}

All available data can be obtained by contacting the corresponding author. All data requests should be submitted to the corresponding author for consideration. Access to anonymized data may be granted following a review.

\section{Disclosure}

The authors report no conflicts of interest in this work.

\section{References}

1. Anselmo MI, Nery M, Parisi MC. The effectiveness of educational practice in diabetic foot: a view from Brazil. Diabetol Metab Syndr. 2010;2(1):45. doi:10.1186/1758-5996-2-45

2. Leone S, Pascale R, Vitale M, Esposito S. Epidemiology of diabetic foot. Infez Med. 2012;20(1):8-13.

3. Fahmida A, Asiful I, Siew HG, Ibrahim K. Honey: a potential therapeutic agent for managing diabetic wounds. $J$ Evid Based Complementary Altern Med. 2014;169130. doi:10.1155/2014/169130

4. Nasiri M, Fayazi S, Jahani S, Yazdanpanah L, Haghighizadeh MH. The effect of topical olive oil on the healing of foot ulcer in patients with type 2 diabetes: a double-blind randomized clinical trial study in Iran. J Diabetes Metab Disord. 2015;14:38. doi:10.1186/s40200-0150167-9
5. Aalaa M, Malazy OT, Sanjari M, Peimani M, Mohajeri-Tehrani M. Nurses' role in diabetic foot prevention and care; a review. J Diabetes Metab Disord. 2012;11(1):24. doi:10.1186/2251-6581-11-24

6. Kalish J, Hamdan A. Management of diabetic foot problems. J Vasc Surg. 2010;51(2):476-486. doi:10.1016/j.jvs.2009.08.043

7. Snyder RJ, Hanft JR. Diabetic foot ulcers-effects on QOL, costs, and mortality and the role of standard wound care and advanced-care therapies. Ostomy Wound Manage. 2009;55(11):28-38.

8. Vileikyte L. Psychosocial and behavioral aspects of diabetic foot lesions. Curr Diab Rep. 2008;8(2):119-125.

9. Wang C, Guo M, Zhang N, Wang G. Effectiveness of honey dressing in the treatment of diabetic foot ulcers: a systematic review and meta-analysis. Complement Ther Clin Pract. 2019;34:123-131. doi:10.1016/j.ctcp.2018.09.004

10. Alami Harandi B, Alami Harandi A, Siavashi B. Diabetic foot ulcer management review of literature. Iran J Surg. 2009;16(4):1-7.

11. Tian X, Yi L-J, Ma L, Zhang L, Song G-M, Wang Y. Effects of honey dressing for the treatment of DFUs: a systematic review. Int $J$ Nurs Sci. 2014;1(2):224-231. doi:10.1016/j.ijnss.2014.05.013

12. Makhdoom A, Khan MS, Lagahari MA, Rahopoto MQ, Tahir SM, Siddiqui KA. Management of diabetic foot by natural honey. $J$ Ayub Med Coll Abbottabad. 2009;21(1):103-105.

13. Huang Y, Xie T, Cao Y, et al. Comparison of two classification systems in predicting theoutcome of diabetic foot ulcers: the Wagner grade and the saint elian wound score systems. Wound Repair Regen. 2015;23(3):379-385. doi:10.1111/wrr.12289

14. Hadadi A, Omdeh Ghiasi H, Hajiabdolbaghi M, Zandekarimi M, Hamidian R. Diabetic foot: infections and outcomes in Iranian admitted patients. Jundishapur J Microbiol. 2014;7(7):e11680. doi:10.5812/ jjm. 11680

15. Surahio AR, Khan AA, Farooq M, Fatima I. Role of honey in wound dressing in diabetic foot ulcer. J Ayub Med Coll Abbottabad. 2014;26 (3):304-306.

16. Mohamed H, Salma MA, Al Lenjawi B, et al. The efficacy and safety of natural honey on the healing of foot ulcers: a case series. Wounds. 2015;27(4):103-114.

17. Hussain MB. Role of honey in topical and systemic bacterial infections. $J$ Altern Complement Med. 2018;24(1):15-24. doi:10.1089/acm.2017.0017

18. Delshad E, Tavakkoli-Kakhki M, Motavasselian M. Successful repair of diabetic foot ulcer with honey-based treatment: a case report. Iran Red Crescent Med J. 2017;19(3):e41939. doi:10.5812/ircmj.41939

19. Elshenawie HA, Ahmed Shalan WE, Aziza EA. Effect of ozone olive oil ointment dressing technique on the healing of superficial and deep diabetic foot ulcers. $J$ Am Sci. 2013;9:235-250.

20. Abooei Mehrizi M, Eidi A, Mortazavi P. Study of effect of olive oil on re-epithelialization of epithelial tissue in excision wound healing model in rats. J Comp Pathophysiol. 2016;13(2):1875-1883.

21. Khadem Haghighian H, Koushan Y, Asgharzadeh AA. Treatment of diabetic foot ulcer with propolis and olive oil: a case report. Knowl Health. 2012;6:35-38.

22. Zahmatkesh M, Rashidi M. Case report of diabetic foot ulcer with topical honey and olive oil. J Med Plants. 2008;36-41.

\section{Publish your work in this journal}

Clinical, Cosmetic and Investigational Dermatology is an international, peer-reviewed, open access, online journal that focuses on the latest clinical and experimental research in all aspects of skin disease and cosmetic interventions. This journal is indexed on CAS.
The manuscript management system is completely online and includes a very quick and fair peer-review system, which is all easy to use. Visit http://www.dovepress.com/testimonials.php to read real quotes from published authors. 